V. Talarico ${ }^{1}$, G. L. Marseglia ${ }^{2}$, M. Lanari ${ }^{3}$, S. Esposito ${ }^{4}$, S. Masi ${ }^{5}$, M. De Filippo ${ }^{2}$, L. GALlelli ${ }^{6}$, A. Licari ${ }^{2}$, R. LUbrano ${ }^{7}$, S. Zampogna ${ }^{1}$, SIMEUP STUdy group

\title{
Pediatric urticaria in the Emergency Department: epidemiological characteristics and predictive factors for its persistence in children
}

\author{
${ }^{1}$ Department of Pediatrics, Pugliese-Ciaccio Hospital of Catanzaro, Catanzaro, Italy \\ ${ }^{2}$ Department of Pediatrics, Fondazione IRCCS Policlinico San Matteo, University of Pavia, Pavia, Italy \\ ${ }^{3}$ Department of Pediatric Emergency, S. Orsola Hospital, Bologna, Italy \\ ${ }^{4}$ Department of Medicine and Surgery, Pediatric Clinic, Pietro Barilla Children's Hospital, University of Parma, Parma, Italy \\ ${ }^{5}$ Department of Pediatrics, Meyer Hospital and University of Firenze, Italy \\ ${ }^{6}$ Department of Pharmacology, Magna Graecia University of Catanzaro, Catanzaro, Italy \\ ${ }^{7}$ Department of Pediatrics, La Sapienza University of Rome, Hospital of Latina, Latina, Italy
}

\section{KeY WORDS}

Acute urticaria; children; trigger

factors; epidemiology; severity.

\author{
Corresponding author \\ Valentina Talarico \\ Department of Pediatrics \\ Pugliese-Ciaccio Hospital of Catanzaro \\ viale Pio $\mathrm{X}$ \\ 88100 Catanzaro, Italy \\ E-mail: talaricovalentina@gmail.com
}

Doi

10.23822/EurAnnACI.1764-1489.148

\begin{abstract}
Summary
Introduction. Acute urticaria $(A U)$ in children is a common clinical manifestation responsible for admission to the emergency department (ED). We aimed to analyze the epidemiological characteristics of $A U$ in children and to identify predictors of both severity and progression. Materials and methods. We evaluated 314 children admitted to the $E D$ with a diagnosis of $A U$. We analyzed information concerning its onset, duration, severity, possible triggering factors, and the persistence of symptoms after 1, 3, and 6 months. Results. The most common etiological factors were infections (43.9\%); in up to $32.4 \%$ of cases, $A U$ was considered as idiopathic. AU was significantly most common in males and pre-school children. At the 6-month follow-up, 9.5\% of children presented a persistence of urticaria, mainly those with contact (44.4\%) or idiopathic (30.4\%) forms. Conclusions. The AU etiology identified by history in the ED may be a significant predictor of persistence after a first attack of $A U$.
\end{abstract}

\section{Introduction}

Acute urticaria (AU) is a common skin disorder characterized by itching, wheals, and/or angioedema with a duration $<6$ weeks. Urticaria is considered chronic when it is recurrent, with signs and symptoms recurring most days of the week, for six weeks or longer (chronic urticaria, CU) $(1,2)$. AU is reported in childhood (3.4\% UK, 4.4\% Germany, 5.4\% Denmark), and its persistence is even less probable $(0.1 \%-0.3 \%)$ (3). The first treatment of urticaria is the elimination of any identified trigger factors and then the use of second-generation antihistamines and corticosteroids (2). A detailed history of the factors that may predict the time and the severity of urticaria will help physicians to perform an appropriate clinical assessment. Several studies described the demographics and the etiologies of AU in children $(4,5)$, but the factors that may influence its duration and severity have not been well addressed.

Therefore, this study aimed to evaluate the prevalence of urticaria in children referred to Emergency Departments (ED) in Italy and to analyze the factors that may predict the duration of the first attack.

\section{Materials and methods}

We performed an observational clinical study on children with AU referred to ten Italian EDs from $1^{\text {st }}$ October 2016 to 1 De- 
cember 2017. The Local Ethics Committees approved the study protocol, and the work was conducted in compliance with the Institutional Review Board/Human Subjects Research Committee requirements and with the Declaration of Helsinki and the Guidelines for Good Clinical Practice criteria.

\section{Population}

Inclusion criteria: patients of both sexes and $<18$ years old, with a diagnosis of $\mathrm{AU}$ in agreement with international guidelines (2) and with no pharmacological treatment before ED evaluation, whose legal guardians signed the informed consent. Exclusion criteria: patients with CU or affected by autoimmune diseases or in treatment with corticosteroids; children whose legal guardians did not sign the informed consent.

\section{Endpoint}

The first endpoint was the evaluation of the characteristics of children with AU. The second endpoint was to determine the factors that could be used to predict the severity and duration of an initial episode of $A U$ in children.

\section{Experimental protocol}

The diagnosis of AU and its management was made in agreement with the European Academy of Allergy and Clinical Immunology (EAACI) international guidelines (2). Children who satisfied the inclusion criteria were evaluated at 1,3 , and 6 months after the ED admission in order to obtain data on the efficacy of treatment and persistence of symptoms. We used a questionnaire ad hoc that included questions concerning the onset of the acute attack, its duration and severity, and the possible triggering factors. The same questionnaire was repeated at follow-up. The etiological diagnosis was mainly carried out through history taking and physical examination. Laboratory investigations were performed based on history and physical examination to identify the underlying cause. The disease activity was assessed with the weekly Urticaria Activity Score (UAS7) score (2).

\section{Statistical analysis}

All data were analyzed using the SPSS statistical program (Microsoft, Redmond, WA, USA) by evaluating the arithmetic characteristics, e.g., mean, geometric mean, standard deviation (SD). Data parameters were checked for normality using the Shapiro-Wilk normality test. Data were analyzed by one-way ANOVA analysis of variance and the $\chi^{2}$ test. Pearson's test was used to evaluate the correlation between urticarial and patients' characteristics. The threshold for statistical significance was set at ${ }^{*} \mathrm{p}<0.05$. SPSS (SPSS Inc., Chicago, USA) software was used for statistical analyses. We defined and labeled this study as exploratory; therefore, we did not perform a power calculation.

\section{Results}

During the study, 314 children (148 females, $47.1 \%$, and 166 males, $52.9 \%$ ) aged $<17$ years (median 70 months, range $2-442$ months) with a diagnosis of $\mathrm{AU}$ that fulfilled the inclusion criteria were enrolled. AU was more common in males than in females $(\mathrm{p}<0.05)$, and in the age range of 0 to 5 years $(50.3 \%)$. Clinical evaluation and laboratory tests documented that the most common forms of AU were para-infectious (43.9\%) and idiopathic (32.4\%) (table I). In particular, the idiopathic form was most common in children 6-10 years old $(\mathrm{p}<0.05)$ and the infectious form in children under five years (table II). Moreover, the frequency of AU was significantly lower $(\mathrm{p}<0.01)$ in children older than ten years compared to the younger ones. Mild urticaria was diagnosed in $40.4 \%$ enrolled children, moderate urticaria in $44.5 \%$, and severe urticaria in $14.9 \%$.

The correlation between the severity of $\mathrm{AU}$ and the age of children, sex, etiology, and family history for allergic diseases is shown in table III. A positive family history for allergy was found in 114 children (36.3\%), and it was significantly more frequent in those with $\mathrm{AU}$ induced by reactions to food $(\mathrm{n}=24$, $54.5 \%$; $<<0.01)$, drugs $(\mathrm{n}=5,45.5 \% ; \mathrm{p}<0.05)$ and contact (n $=8,44.4 \% ; \mathrm{p}<0.05)$ compared to children with idiopathic $(\mathrm{n}=$ $31,30.4 \%)$ or infectious $(\mathrm{n}=46,33.3 \%)$ urticaria.

Drug treatment was given in 290 children $(92.4 \%)$, and most commonly used drugs were antihistamines $(\mathrm{p}<0.01)$ in monotherapy $(\mathrm{n}=166 ; 57.3 \%)$ or with corticosteroids $(\mathrm{n}=110 ; 37.9 \%)$.

During follow-up, $10.8 \%$ of children presented a recurrence of urticaria in the first month, $11 \%$ at three, and $9.5 \%$ at six months. The factors associated with the recurrence of AU are reported in table IV. Severity, sex, and familiarity did not seem to correlate with the persistence of urticaria. The ages that had had a greater tendency to $\mathrm{CU}$ (in particular at six months) were 5-10 years old and 10-15 years old. In particular, urticaria recurrences were most common in the contact (44.4\%) and idiopathic (30.4\%) forms without differences during the follow-up (figure 1).

\section{Discussion}

In this study, we analyzed epidemiologic data of children with AU admitted to ED; also, we evaluated several significant factors that may predict the severity of an initial episode of AU in children and its progression to a chronic form. AU is a common cause of admission of children to the ED, and it is estimated to affect $15 \%-25 \%$ of people at some point in their life $(4,6)$, commonly adult females $(7,8)$. In a register-based study, Ghazanfar et al. (9) recently documented that women were more frequently diagnosed with urticaria than men, probably because men are less likely to seek medical attention than women. In contrast, in our study, urticaria was more common in males and 
Table I - Clinical characteristic of urticaria in children enrolled in the study.

\begin{tabular}{lcccc}
\hline Urticaria & Total & Male & Female & \% \\
\hline Idiopathic & 101 & 48 & 53 & $32.4 \%$ \\
\hline Infectious & 139 & 75 & 64 & $43.9 \%$ \\
\hline Food & 43 & 27 & 16 & $14.0 \%$ \\
\hline Drugs & 12 & 9 & 3 & $3.5 \%$ \\
\hline Poison & 1 & $/$ & 1 & $0.3 \%$ \\
\hline Contact & 18 & 7 & 11 & $5.7 \%$ \\
\hline
\end{tabular}

Table II - Difference in the age of children with urticaria enrolled in the study.

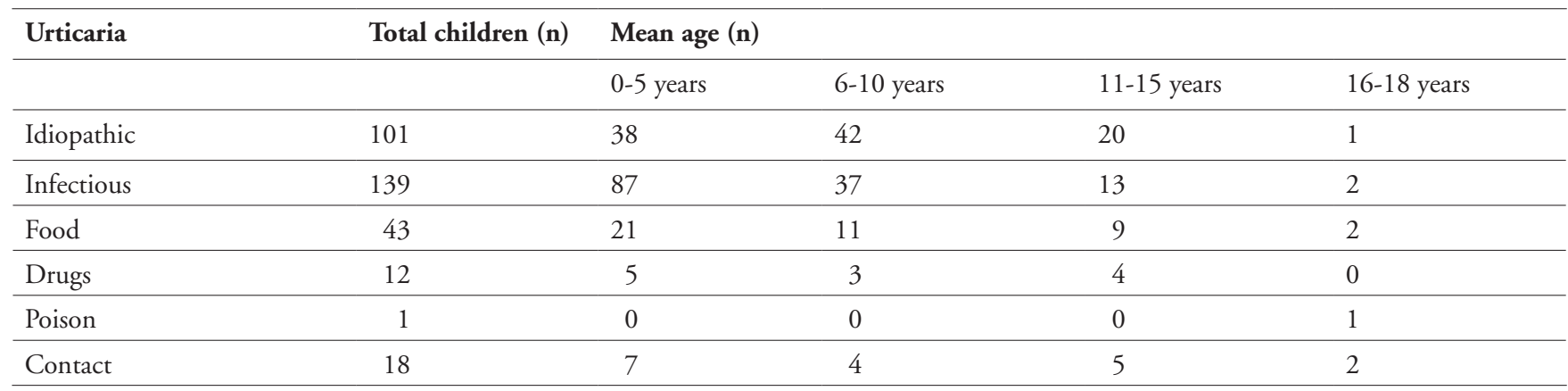

Table III - Relationship between gravity of urticaria and sex, age, etiology, and familiarity for allergy.

\section{GRAVITY}

\begin{tabular}{|c|c|c|c|c|}
\hline & & $\begin{array}{c}\text { MILD } \\
\text { n.127 (40.4\%) }\end{array}$ & $\begin{array}{l}\text { MODERATE } \\
\text { n.140 (44.5\%) }\end{array}$ & $\begin{array}{c}\text { HIGH } \\
\text { n. } 47(14.9 \%)\end{array}$ \\
\hline \multirow[t]{4}{*}{ Physician-diagnosed cause of urticaria } & Idiopathic & 46 & 39 & 16 \\
\hline & Food & 18 & 14 & 11 \\
\hline & Drugs & 6 & 5 & 1 \\
\hline & Contact & 2 & 11 & 5 \\
\hline \multirow[t]{2}{*}{ Sex } & Female & 63 & 62 & 23 \\
\hline & Male & 64 & 78 & 24 \\
\hline \multirow[t]{2}{*}{ Age } & $0-5$ years & 76 & 66 & 16 \\
\hline & $16-18$ years & 2 & 4 & 2 \\
\hline With family allergic history & & 43 & 51 & 20 \\
\hline
\end{tabular}


in pre-school children suggesting that probably age-related sex hormones can play a role in the pathogenesis of urticaria.

Previous studies reported that infections are involved in the development of AU in children (3-5, 10). Infections were the most common potential triggers of attacks of AU in the present study, occurring in $43.9 \%$ of the patients and mainly represented by upper respiratory tract infections. The observed frequency rate is similar to that reported in other studies $(11,12)$.

Bacterial infections of the teeth and the tonsils (e.g., with streptococci) and gastrointestinal infections (e.g., Helicobacter pylori infection) have been described as potential triggers of AU. Nevertheless, the exact role and pathogenesis of mast cell activation by infectious processes remains unclear (13).

Moreover, new episodes of infection are accompanied by reappearance or aggravation of urticaria symptoms, causing chronic spontaneous urticaria $(3,14)$.

In our study, a clear etiology of AU has not been identified in $32.4 \%$ of children (idiopathic urticaria), in agreement with literature data $(15,16)$. AU secondary to food was found in $14 \%$ of the patients. The predominant foods that cause urticaria are milk, eggs, peanuts, tree nuts, fish, and shellfish. Foods were reported to be the possible cause of attacks of AU in $0.9 \%$ and $1.3 \%$, respectively, of patients in two previous studies $(11,12)$; however, Juhlin reported that foods and drinks were associated with exacerbation of wheals in $30 \%$ and $18 \%$, respectively, of patients with recurrent attacks of urticaria (17).

Drug treatment used in the management of urticaria was administered in agreement with international guidelines considering the severity of symptoms (e.g., intense pruritus, angioedema) $(4,18)$. Therefore, we documented that antihistamines were the most common drug used. We did not record any adverse drug reaction, probably because the short duration of treatment.

We found that specific triggers of AU were not associated with severe urticaria, even if we found that unknown causes were significantly associated with mild urticaria and infectious triggers with a moderate one. Also, we found that pre-school children had more frequent mild urticaria $(\mathrm{p}<0.04)$. AU has been defined as spontaneous wheals presenting for less than six weeks $(1,19)$. However, its duration is related to the clinical presentation of disease (15, 20). Therefore, a detailed understanding of the related factors that may influence the duration of AU will help primary physicians to perform a more appropriate clinical assessment. So, we aimed to

Table IV - Related factors associated with the recurrence of an initial episode acute urticaria in children.

\begin{tabular}{|c|c|c|c|c|}
\hline \multicolumn{5}{|c|}{ RECURRENCE } \\
\hline \multirow[t]{5}{*}{ Physician-diagnosed cause of urticaria } & Idiopathic & 10 & 11 & 10 \\
\hline & Infectious & 8 & 6 & 4 \\
\hline & Food & 4 & 4 & 2 \\
\hline & Poison & I & l & 1 \\
\hline & Contact & 4 & 3 & 2 \\
\hline \multirow[t]{2}{*}{ Sex } & Female & 13 & 13 & 10 \\
\hline & Male & 13 & 13 & 8 \\
\hline \multirow{2}{*}{ Age } & $11-15$ years & 5 & 5 & 4 \\
\hline & $16-18$ years & 3 & 2 & 0 \\
\hline \multirow[t]{3}{*}{ Severity } & Mild & 11 & 9 & 4 \\
\hline & Moderate & 10 & 11 & 8 \\
\hline & High & 5 & 6 & 6 \\
\hline With family allergic history & & 9 & 11 & 10 \\
\hline
\end{tabular}


Figure 1 - Detailed information on the relationship between etiologies of the first attacks of urticaria and recurrence of urticaria at one, three and six months.

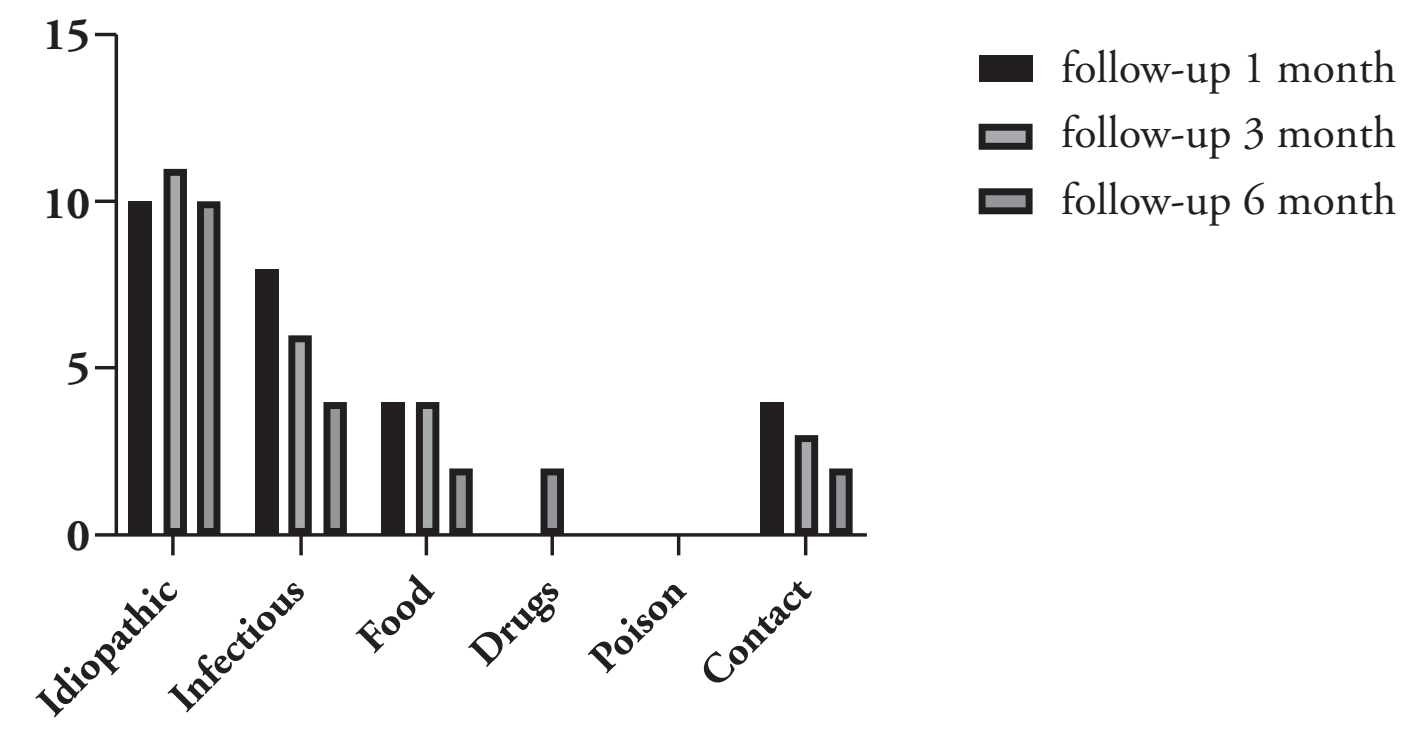

determine if there were differences in demographic and clinical characteristics in children that had an AU that will progress more probably to CU, with the persistence of symptoms in follow-up at three and six months after the first attack.

We analyzed if there were some patient-related factors associated with persistent urticaria such as age, sex, etiology, severity, and family history. Sex was not a statistically significant factor associated with the duration of urticaria. Children 5-10 years old and 10-15 years old had a greater tendency to CU, with symptoms remaining at six months of $6 \%$ and $7 \%$, respectively. About etiology, the higher prevalence of urticaria has been observed in the group with unknown etiology (10\%). Severity and familiarity did not seem to correlate with the persistence of urticaria.

The present study has some limitations. Firstly, we have not recorded laboratory data (for example, white blood cell, C-Reactive Protein) because current guidelines do not recommend routine diagnostic tests or extended diagnostic programs in patients with acute urticaria. Moreover, we did not record the total number of accesses of urticaria in pediatric age in Italy, even if the reported data are recorded in several cities of Italy and probably could represent a model of Italian reality.

\section{Conclusions}

We believe that the identification of children with AU who have a high risk of progression to CU is essential for better diagnostic and therapeutic management. We think that a good quality standardized questionnaire aimed to identify specific high-risk factors, together with a detailed physical examination, can provide important data related to the progression from $\mathrm{AU}$ to $\mathrm{CU}$ and guide the follow-up.

\section{Acknowledgments}

The authors thank for the contribution the SIMEUP study group members: V. Corsi, F. Di Pietro, A. Dondi, G. Bolasco, M. C. Gigliotti, R. Nigro, E. Panfili, P. Pavone, G. M. Terragni.

\section{Conflict of interests}

The authors declare that they have no conflict of interests.

\section{References}

1. Bernstein JA, Lang DM, Khan DA, et al. The diagnosis and management of acute and chronic urticaria: 2014 update. J Allergy Clin Immunol 2014;133(5):1270-1277.

2. Zuberbier T, Aberer W, Asero R, et al. The EAACI/GA(2) LEN/ $\mathrm{EDF} / \mathrm{WAO}$ guideline for the definition, classification, diagnosis, and management of urticaria: the 2013 revision and update. Allergy 2014;69(7):868-887.

3. Kudryavtseva AV, Neskorodova KA, Staubach P. Urticaria in children and adolescents: An updated review of the pathogenesis and management. Pediatr Allergy Immunol 2019;30(1):17-24.

4. Liu TH1, Lin YR, Yang KC, et al. Significant factors associated with severity and outcome of an initial episode of acute urticaria in children. Pediatr Allergy Immunol 2010;21(7):1043-51. 
5. Toubi E, Kessel A, Avshovich N, et al. Clinical and laboratory parameters in predicting chronic urticaria duration: a prospective study of 139 patients. Allergy 2004;59(8):869-73.

6. Mortureux P, Leaute-Labreze C, Legrain-Lifermann V, et al. Acute urticaria in infancy and early childhood: a prospective study. Arch Dermatol 1998;134(3):319-23.

7. Syue YJ, Li CJ, Chen WL, et al. Significant predictive factors of the severity and outcomes of the first attack of acute angioedema in children. BMC Pediatr 2019;19(1):423.

8. Dhami S, Sheikh A. Anaphylaxis: epidemiology, aetiology and relevance for the clinic. Expert Rev Clin Immunol 2017;13(9):889-95.

9. Ghazanfar MN, Kibsgaard L, Thomsen SF, et al. Risk of comorbidities in patients diagnosed with chronic urticaria: A nationwide registry-study. World Allergy Organ J 2020;13(1):100097.

10. Lipozencic' J, Wolf R. Life-threatening severe allergic reactions: urticaria, angioedema, and anaphylaxis. Clin Dermatol 2005;23(2):193-205.

11. Comert S, Celebioglu E, Karakaya G, et al. The general characteristics of acute urticaria attacks and the factors predictive of progression to chronic urticaria. Allergol Immunopathol (Madr) 2013;41(4):239-45.
12. Kulthanan K, Chiawsirikajorn Y, Jiamton S. Acute urticaria: etiologies, clinical course and quality of life. Asian Pac J Allergy Immunol 2008;26(1):1-9.

13. Wedi B, Raap U, Wieczorek D, Kapp A. Urticaria and infections. Allergy Asthma Clin Immunol 2009;5(1):10.

14. Church MK, Weller R, Stock P, Maurer M. Chronic spontaneous urticaria in children: itching for insight. Pediatr Allergy Immunol 2011;22(1):1-8.

15. Kanani A, Schellenberg R, Warrington R. Urticaria and angioedema. Allergy Asthma Clin Immunol 2011;7(Suppl 1):S9.

16. Poonawalla T, Kelly B. Urticaria: a review. Am J Clin Dermatol 2009;10(1):9-21.

17. Juhlin L. Recurrent urticaria: clinical investigation of 330 patients. Br J Dermatol 1981;104(4):369-81.

18. Khakoo G, Sofianou-Katsoulis A, Perkin MR, et al. Clinical features and natural history of physical urticaria in children. Pediatr Allergy Immunol 2008;19(4):363-6.

19. Lin YR, Liu TH, Wu TK, et al. Predictive factors of the duration of a first-attack acute urticaria in children. Am J Emerg Med 2011;29(8):883-9.

20. Weldon D. Quality of life in patients with urticaria and angioedema: assessing burden of disease. Allergy Asthma Proc 2014;35(1):4-9. 